\title{
Estudo Iconográfico de Chapadão do Lageado para aplicação no Design de artefatos de lembranças
}

Iconographic study of Chapadão do Lageado for application in remembrance artifact design

OURIVES, Eliete Auxiliadora Assunção; Pós Doutorada; Universidade Federal de Santa Catarina elieteourives@gmail.com

FIGUEIREDO, Luiz Fernando Gonçalves; Pós Doutorado; Universidade Federal de Santa Catarina

Iff@cce.ufsc.br

DIAS, Franciele Vieira; Graduanda; Universidade Federal de Santa Catarina

franciele.vd@outlook.com

VICTORIA, Isabel Cristina Moreira; Mestranda; Universidade Federal de Santa Catarina

Isabel.mvictoria@gmail.com

\section{Resumo}

Este artigo visa demonstrar o processo de pesquisa e de projeto de artefatos de recordação a partir do estudo iconográfico do município de Chapadão do Lageado realizado com o apoio da prefeitura, do Núcleo de Abordagem Sistêmica do Design (NASDesign) localizado no Centro de Comunicação e Expressão (CCE) da Universidade Federal de Santa Catarina (UFSC) e a AMPE do Alto Vale. Por meio desse estudo foram verificadas possibilidades de planejamento de aplicações no design de mobiliário a partir de um estudo etnográfico da região do Alto Vale do Itajaí, visando agregação de valor cultural.

Palavras Chave: Chapadão do Lageado. Ícones. Design. Design de mobiliário.

\begin{abstract}
This article aims to demonstrate the process of research and remembrance artifact design from the iconographic study of the Chapadão do Lageado town, located in Upper Itajai Valley with the help of the Town hall and the Center for Systems Approach to Design (NASDesign) located at the Center for Communication and Expression (CCE) of the Federal University of Santa Catarina (UFSC) and AMPE from Upper Valley. Through this study were verified possibilities of planning applications in the design of buttons, furniture, creating a collection based on photographs and analysis of windows, doors and facades of homes, as well as historical monuments and landscape of the region in order aggregation of cultural value.
\end{abstract}

Keywords: Chapadão do Lageado, Icons, Design, furniture Design. 


\section{Introdução}

O que se pretende com este trabalho, que está sendo desenvolvido em parceria com a prefeitura de Chapadão do Lageado e com o Núcleo de Abordagem Sistêmica do Design (NASDesign), é realizar um estudo da história e da cultura de um dos municípios mais jovens da região do Alto Vale do Itajaí em Santa Catarina que é Chapadão do Lageado, especificamente no que se refere aos seus colonizadores (portugueses, alemães e Italianos) e Índios Xokleng (Figura 1) e a sua representação por meio de modelos iconográficos aplicados ao design.

Chapadão do Lageado, emancipado em 1995, tem sua economia baseada na agricultura e serviços, possuindo grande potencial para o ecoturismo e turismo religioso. Este estudo, além de congregar aspectos culturais locais, processos, produtos e serviços, proporciona a estes, um diferencial que desperta o interesse da sociedade, pois agrega valor cultural.

O objetivo é fortalecer, resgatar e divulgar referências culturais de Chapadão do Lageado, por meio do design. Os ícones serão utilizados como padrões e elementos gráficos, formas, cores, etc., e irão fornecer à sociedade a mensagem cultural de raiz do local. Essas imagens iconográficas serão a representação simbólica dos povos mais antigos da região do Alto Vale conferindo-lhe identidade local e cultural.

Figura 1 - Colonizadores e Índios na região do Alto Vale do Itajaí

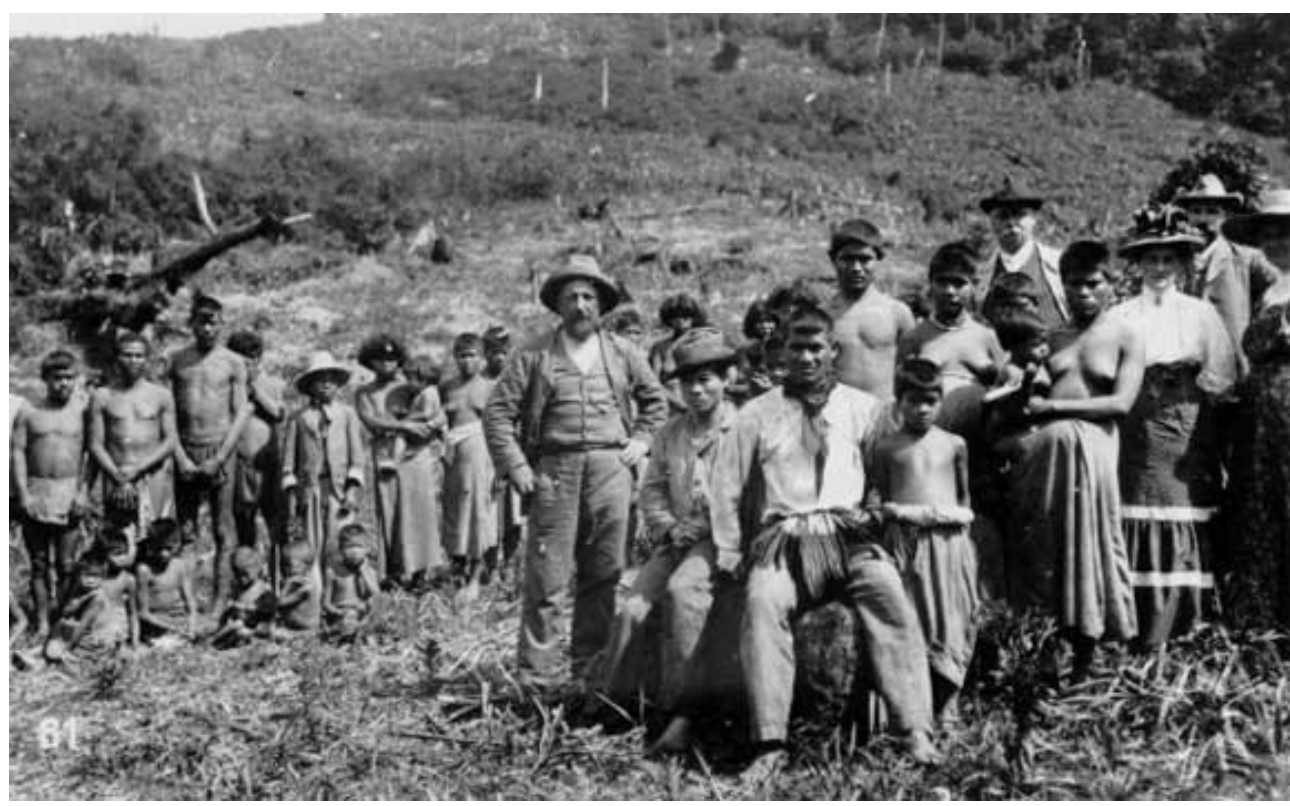

Fonte: https://pib.socioambiental.org/pt/povo/xokleng/976 (1929)

Este trabalho, teve como base o estudo iconográfico do Ribeirão da Ilha para aplicação no design de joias, que teve como objetivo o estudo iconográfico por meio do resgate cultural característico da arquitetura barroca do Ribeirão da llha. A partir de pesquisas e registros fotográficos do local, foram criados mapas morfológicos (Figura 2) com a decomposição de formas características da arquitetura local, painéis semânticos de referência e posteriormente foi criado um mapa de ícones (Figura 3) para a criação de um produto, que neste caso, teve como resultado um anel (Figura 4). 
Figura 2 - Mapa Morfológico arquitetura Ribeirão da Ilha

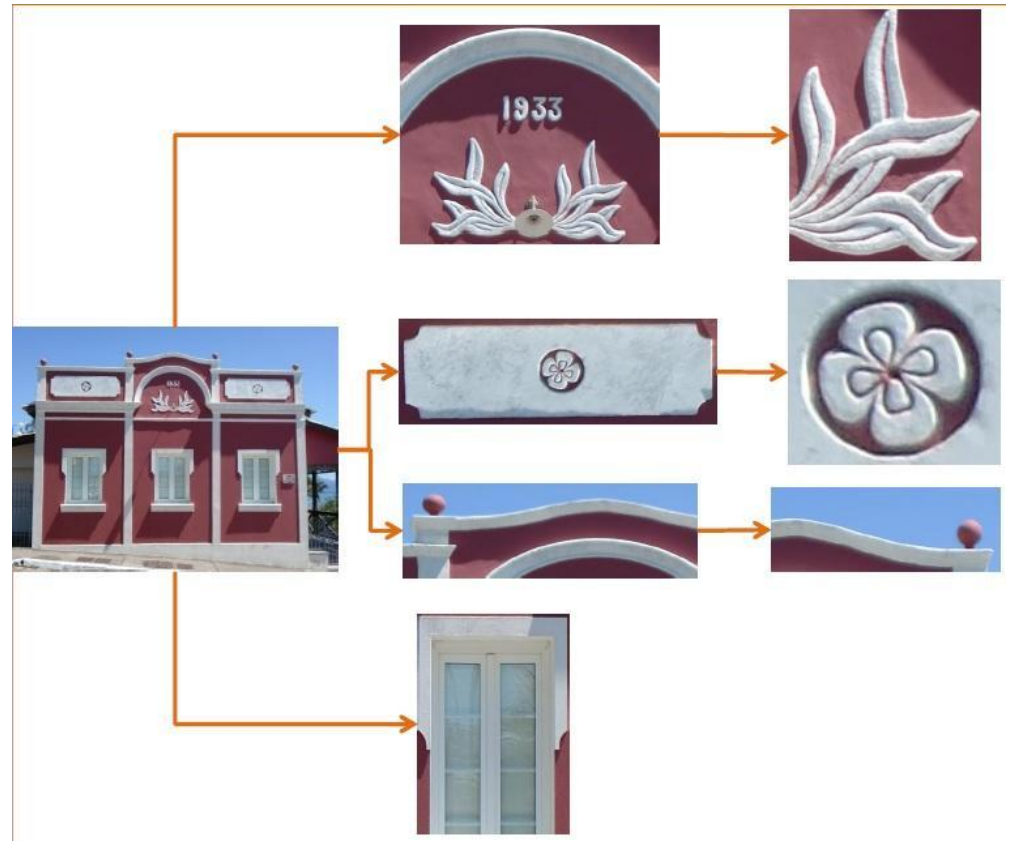

Fonte: OURIVES et al. (2012)

Figura 3-Mapa de ícones

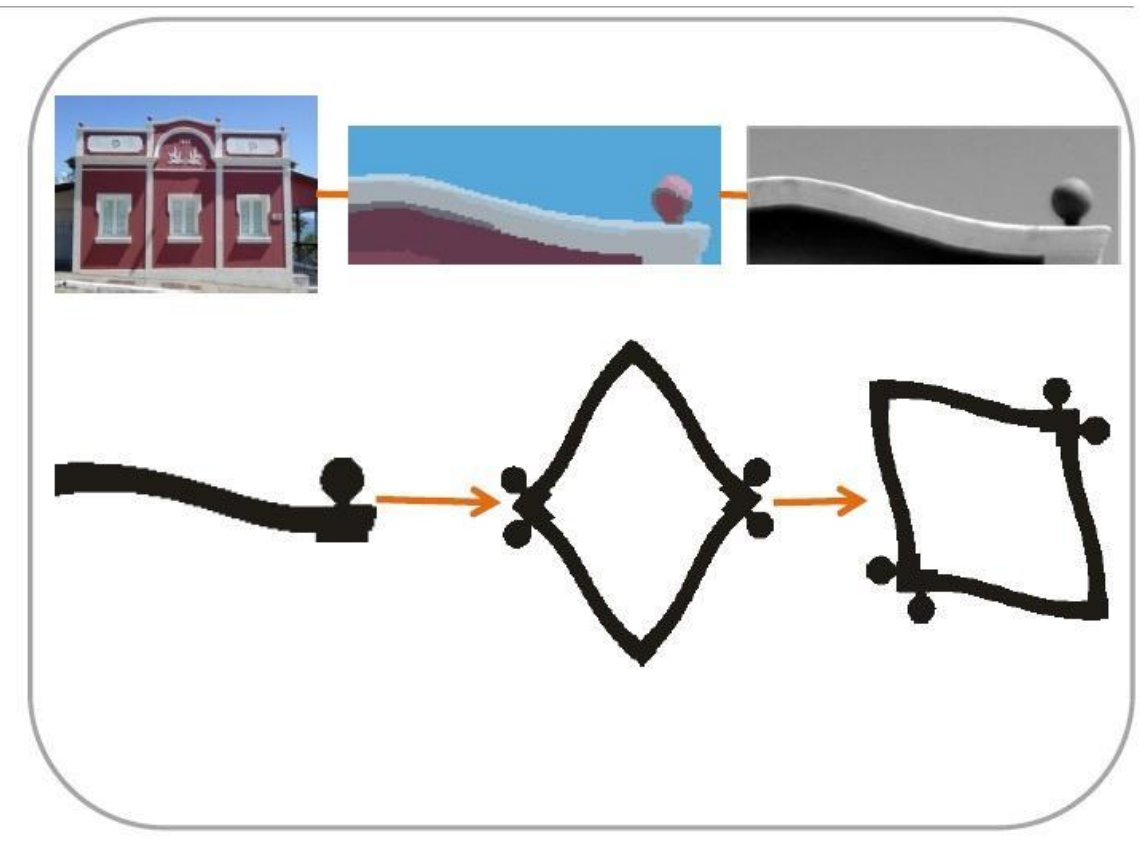

Fonte: OURIVES et al. (2012) 
Figura 4 - Resultado Final - Anel

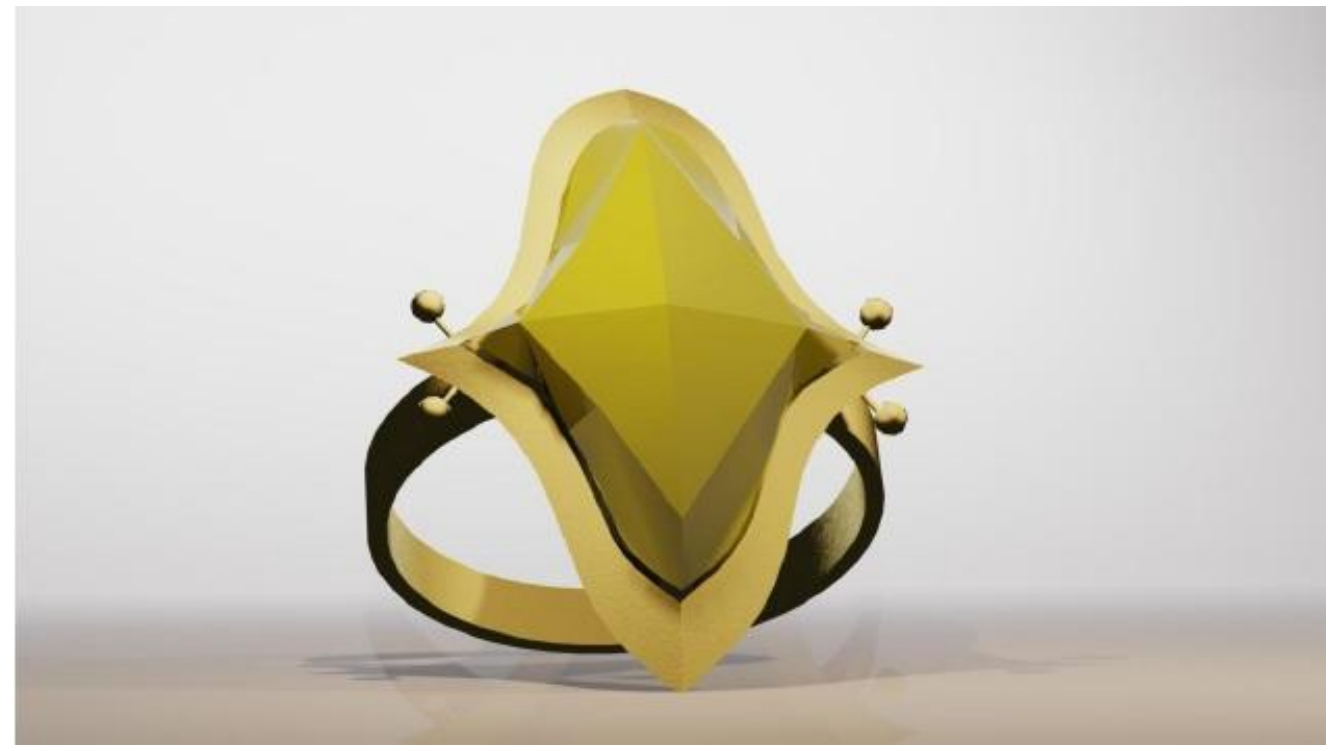

Fonte: OURIVES et al. (2012)

Sendo assim, pode-se afirmar que o estudo e o desenvolvimento da forma, como também as possibilidades de aplicação a partir de elementos observados e extraídos da cultura do local, no caso os povos antigos que formaram a sociedade contemporânea de Chapadão do Lageado, aplicados nas diferentes áreas do design como produtos, gráfico, promocional, entre outros.

\subsection{Objetivos}

O principal objetivo deste trabalho é realizar um estudo iconográfico por meio de um estudo etnográfico da região do Alto Vale do Itajaí, buscando assim, o resgate cultural de raiz característico dos povos que habitaram essa área nos séculos XIX e XX, para aplicação em design através das oportunidades identificadas.

Além desse, os objetivos específicos são reconhecer elementos que caracterizavam esses povos; resgatar a referência cultural por meio do desenvolvimento de ícones, imagens, etc; e fortalecer a referência cultural de raiz por meio da aplicação de ícones e imagens em produtos de design visando, futuramente, a produção de joias, eco joias, mobiliários, estampas e outros produtos identificados para a comercialização e com isso a valorização dos mesmos.

\subsection{Metodologia}

Este trabalho caracteriza-se como uma pesquisa de abordagem qualitativa, ou seja, existe uma relação entre o mundo real, o sujeito e a subjetividade do sujeito que não permite ser traduzido em números e se torna uma pesquisa de abordagem quantitativa. A atribuição de significados e a interpretação são básicas no processo.

É descritiva, pois o pesquisador é o instrumento-chave e tende a analisar os dados indutivamente. A abordagem tem como principal foco a significação do processo (Figura 5).

Além disso, é uma pesquisa exploratória, pois envolve um estudo etnográfico da região do Alto Vale do Itajaí, na intenção de buscar a familiarização com o assunto, de modo a torná-lo mais explícito. 


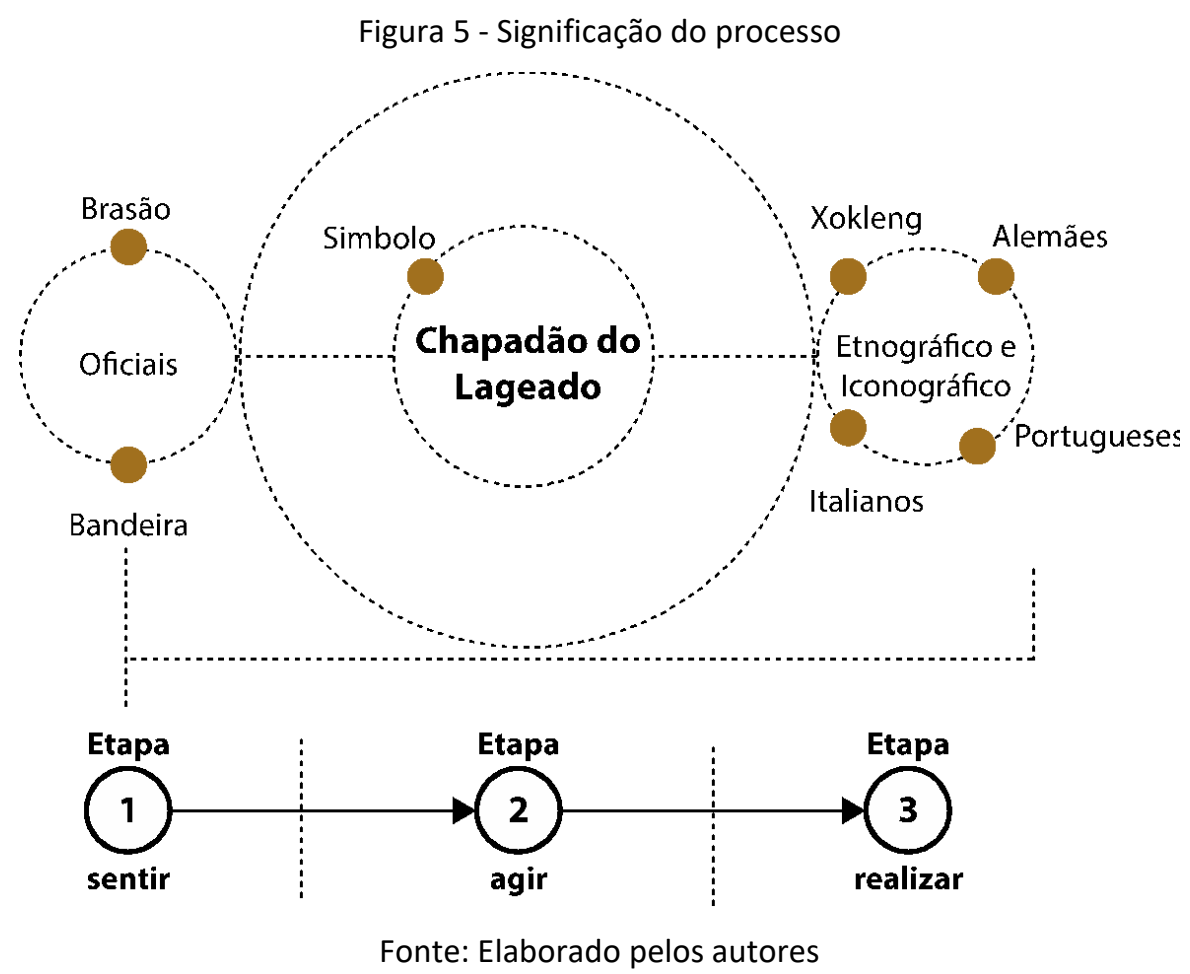

No desenvolvimento prático, foram desenvolvidas 4 etapas conforme demonstrado a seguir:

Etapa 1: Este projeto iniciou por meio de uma pesquisa etnográfica a partir do levantamento de informações e imagens fotográficas, visando o registro de referências próprias e características dos povos da região do Alto Vale que pudessem expressar a sua identificação cultural visual de raiz.

Sendo assim, realizou-se nessa primeira etapa a pesquisa em publicações de materiais impressos e digitais.

Etapa 2: Por meio da construção de mapas mentais (Figura 6), diagrama de origem (Figura 7) e painéis semânticos (Figuras 8, 9, 10,11,12), realizou-se a análise, a organização e a estruturação das informações.

Primeiramente, construíram-se os mapas morfológicos, por meio da decomposição de formas selecionadas, consideradas importantes para cada contexto e utilizadas como referência própria e característica dos povos antigos do Alto Vale, que pudessem expressar a sua identificação cultural visual.

Os mapas foram utilizados como ferramenta para organização do pensamento e utilizaram os princípios dos mapas mentais, "Um Mapa Mental é a maneira mais fácil de introduzir e de extrair informações do seu cérebro - é uma forma criativa e eficaz de anotar que literalmente "mapeia" seus pensamentos." (BUZAN, 2005, p. 24, grifo do autor).

Além disso, os mapas mentais podem ajudar, principalmente no processo de elaboração de projetos de design, e segundo Buzan (2005, p. 30): "ser mais criativo; ganhar mais tempo; resolver problemas; concentrar-se; organizar e clarear os pensamentos [...]; planejar [...]". 
Figura 6 - Mapa mental

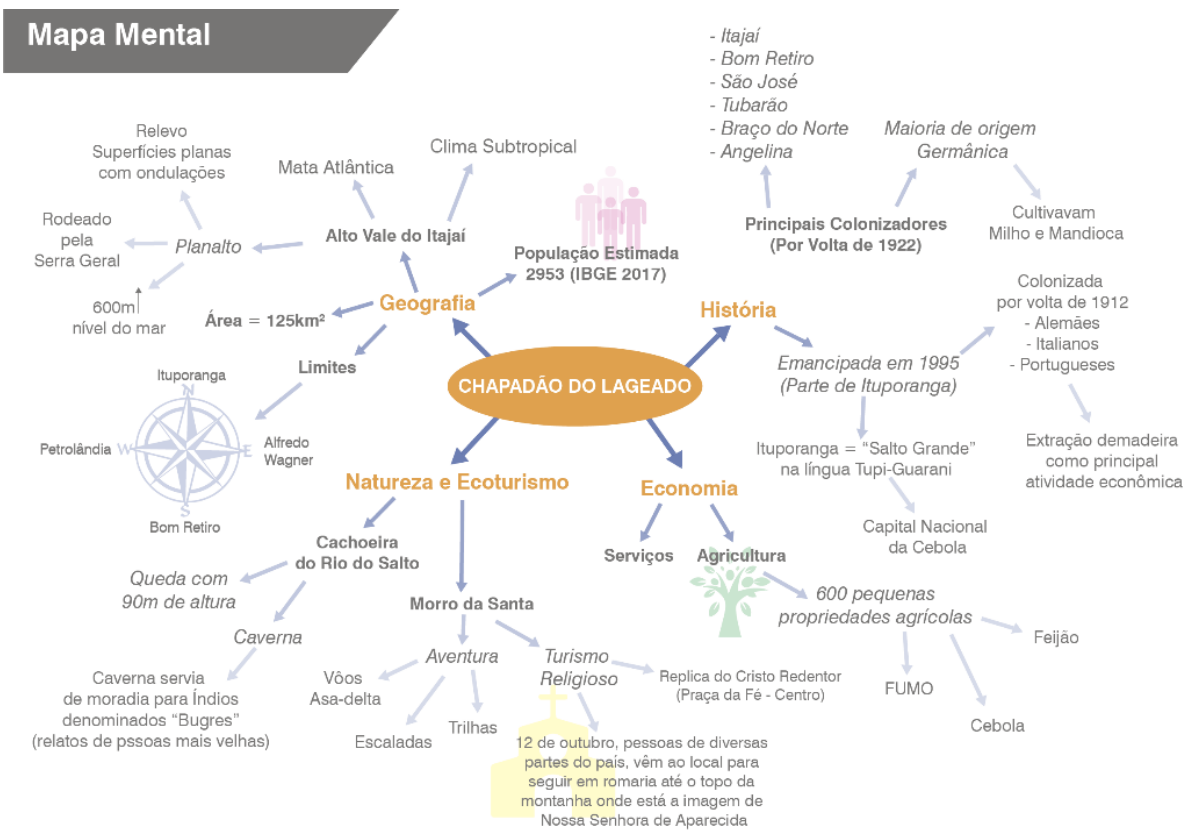

Fonte: Elaborado pelos autores

Figura 7 Diagrama da origem de Chapadão do Lageado

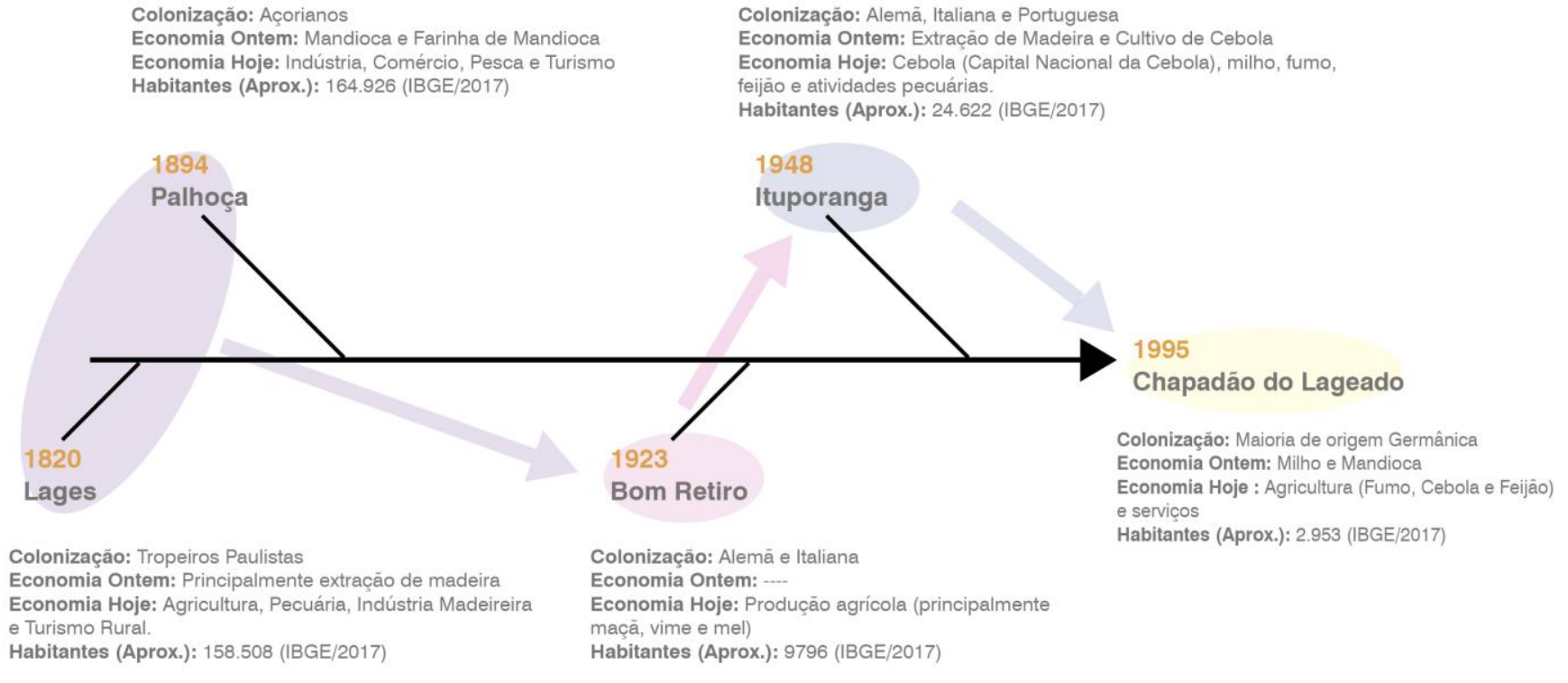

Fonte: Elaborado pelos autores 
Figura 8 - A semântica do brasão de Chapadão do Lageado

O Brasăo do Município de Chapadão do Lageado foi criado em 31 de outubro de 1997

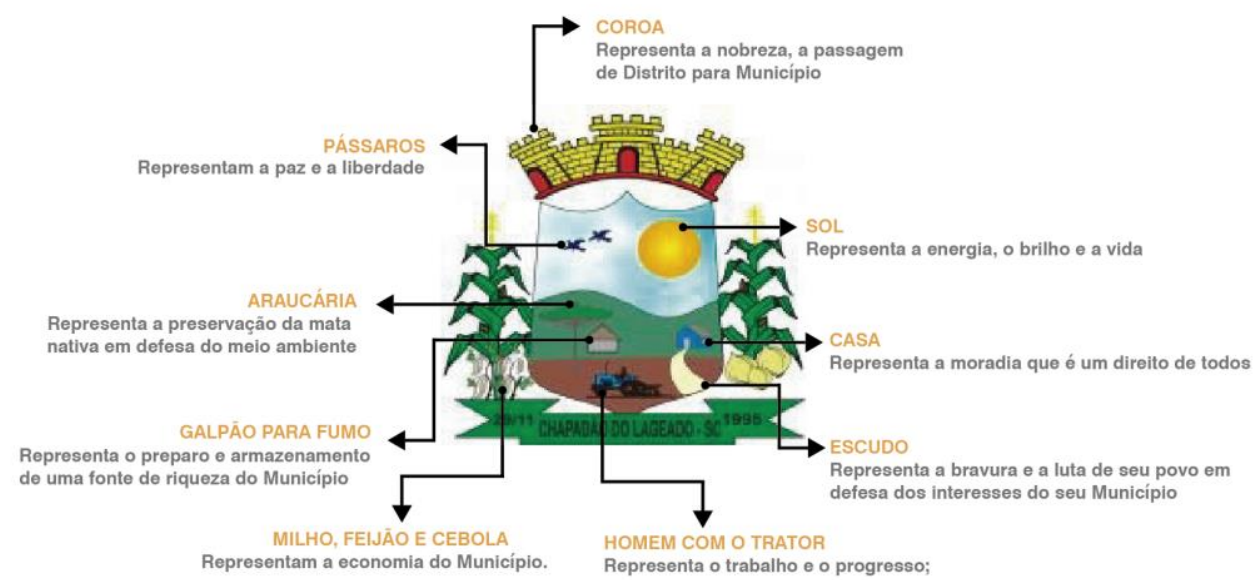

Fonte: http://www.chapadaodolageado.sc.gov.br/cms/pagina/ver/codMapaltem/40587 (2014)

Com o objetivo de complementar os mapas, os painéis semânticos foram elaborados visando explorar as possibilidades de aplicação no design para auxiliar na visualização e conceituação do universo dos produtos. Os painéis semânticos, por exemplo, são usados em algumas publicações específicas do design de moda, de móveis e arquitetura de interiores (PANTONE, 2009; WGSN, 2009) para ilustrar tendências e nortear os profissionais da área. Além disso, podem transformar a linguagem escrita em linguagem visual, ou seja, a busca por imagens que identifiquem os termos listados, ou as necessidades que se procura atender durante a elaboração de um projeto.

Figura 9 - Painel Semântico Xokleng

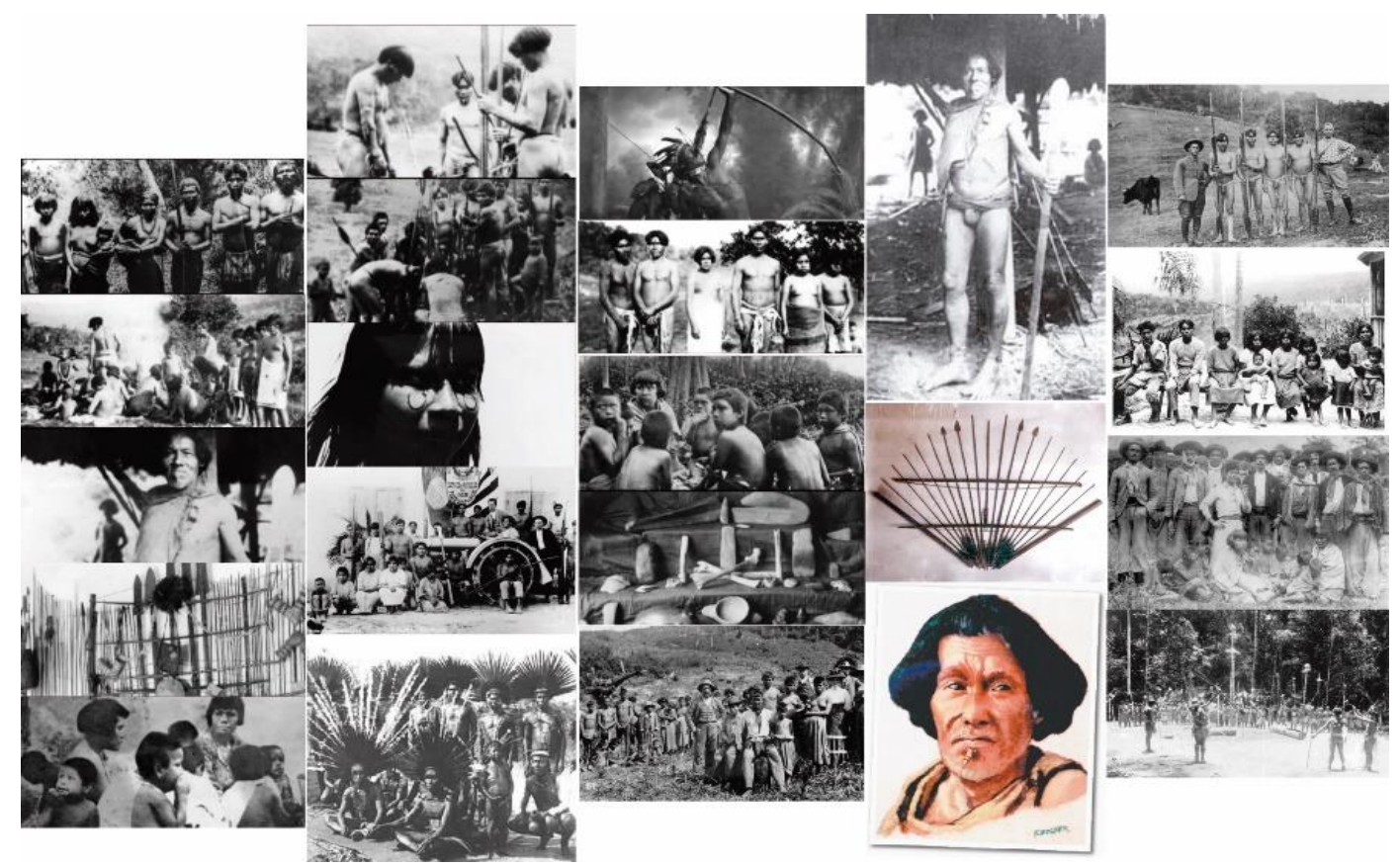

Fonte: Elaborado pelos autores 
Figura 10 - Painel Semântico Alemães
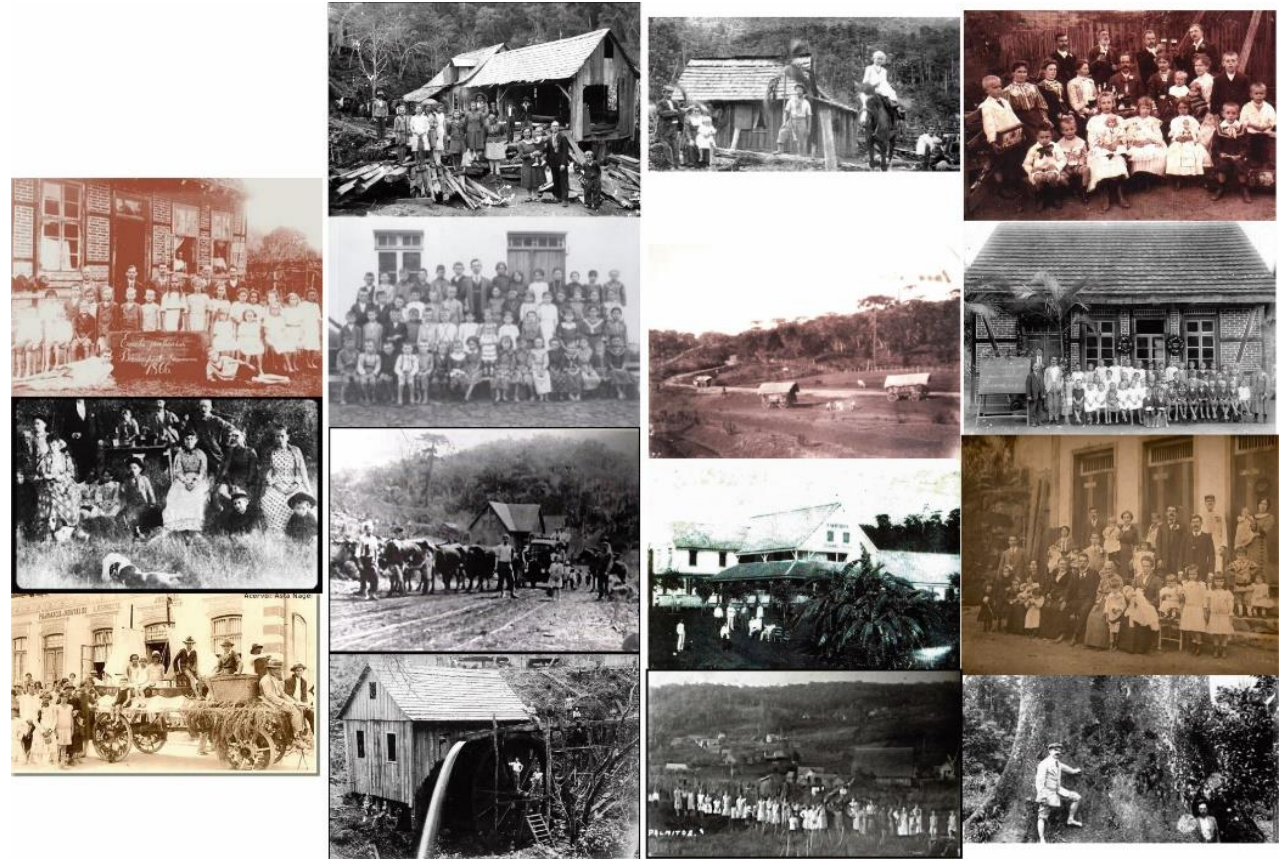

Fonte: Elaborado pelos autores

Figura 11 - Painel Semântico Italianos
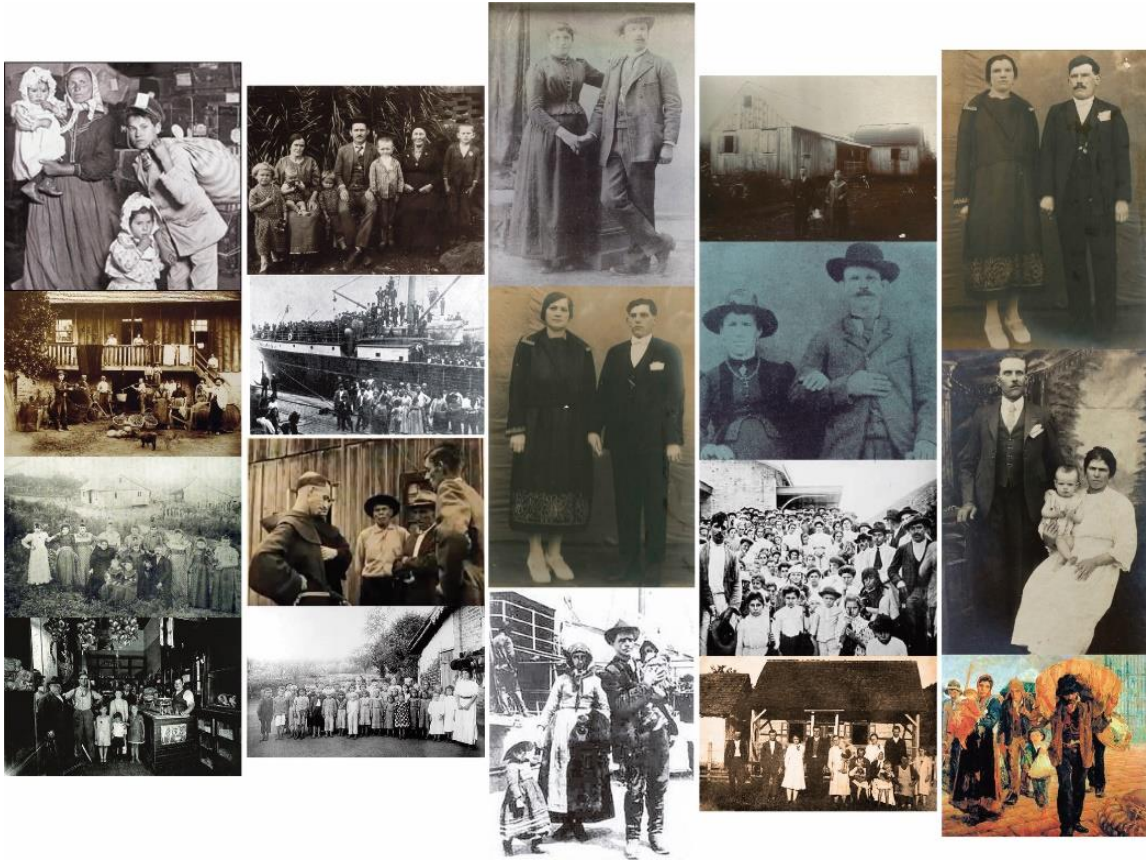

Fonte: Elaborado pelos autores 
Figura 12 - Painel Semântico Portugueses
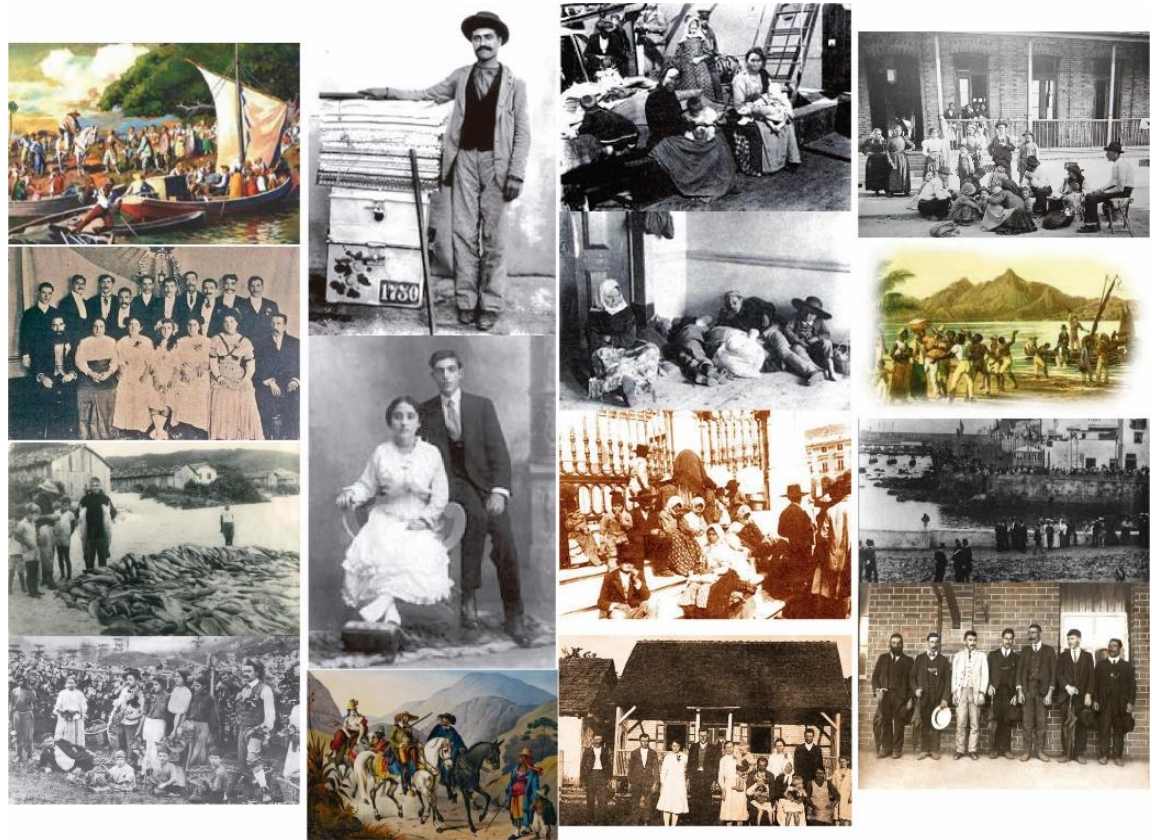

Fonte: Elaborado pelos autores

A partir do desenvolvimento dos painéis semânticos da cultura de raiz, foi construído um painel de referencial (Figura 13) semântico, para assim, buscar uma recorrência dos aspectos formais (cor, forma, composição) que coincidem com as semânticas retiradas do mapa conceitual, elaborado por meio de informações secundárias da região.

Figura 13 - Painel Referencial Semântico

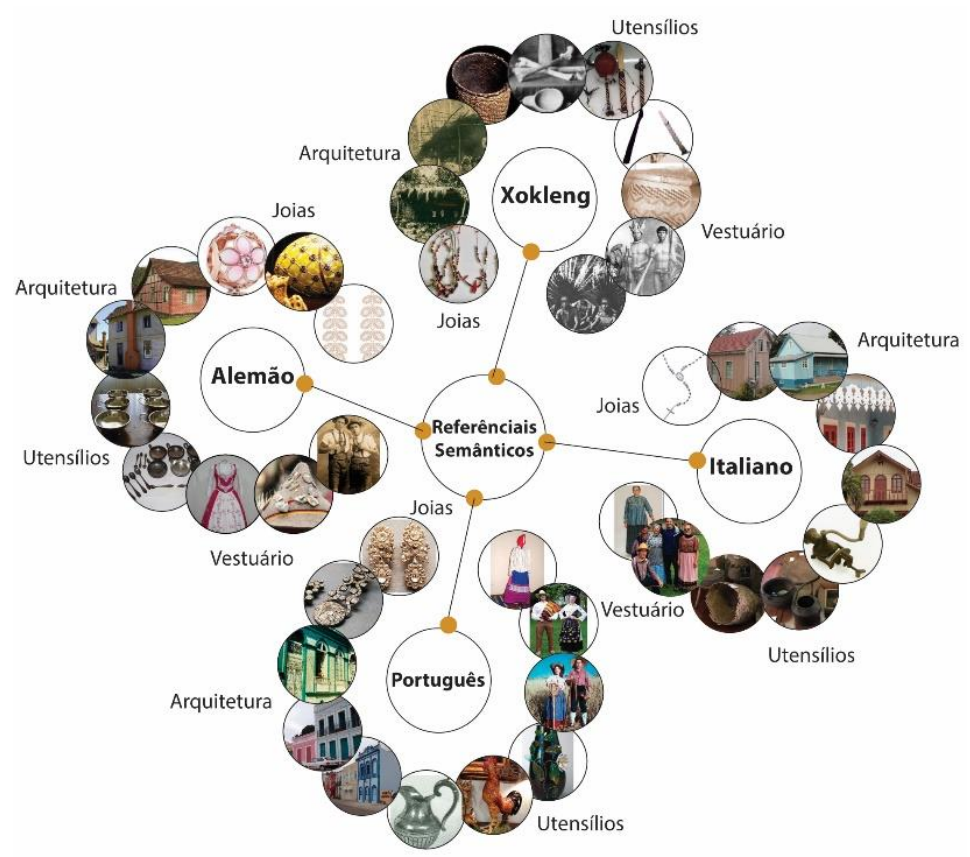


Fonte: Elaborado pelos autores

Etapa 3: Nesta etapa, será desenvolvido os ícones a partir das informações elucidadas na Etapa 2. Este processo será determinado pela abstração e pela composição das formas baseado no estilo Mono Crest.

Mono Crest, segundo (AROS et al., 2015), é um estilo ligado ao modo gráfico-idealista. Para alcançar uma simplicidade visual, não se utiliza de texturas, volume ou tonalidades, apenas linhas básicas e sem variação de espessura como elemento de representação, e "[...] busca constituir um discurso simbólico que reforça a tradição, busca revelar uma valorização das origens, da história e da essência. Sua principal inspiração são os brasões, que dá origem ao próprio nome do estilo "Mono Brasão".

Após essa definição, percebe-se como a inspiração no estilo Mono Crest é essencial, pois o mesmo possui um conceito intrínseco de identidade, prezando pela valorização da história e cultura, além de ser minimalista, o que facilita a reprodução dos ícones que serão gerados nas próximas etapas do projeto.

Etapa 4: Nesta etapa, será realizada a materialização dos produtos gerados a partir dos ícones inspirados no estilo Mono Crest, a serem desenvolvidos na Etapa 3.

\section{NASDesign e a elaboração de artefatos: Chapadão do Lageado}

O NASDesign, localizado no Centro de Comunicação e Expressão da UFSC, trabalha a partir de necessidades e problemas, utilizando-se da pesquisa e do desenvolvimento para aplicar os conhecimentos em design. Em vista disso, desde 2006, o grupo trabalha com projetos no Estado de Santa Catarina que possuem cunho social.

Sendo assim, torna-se necessário a partir de estratégias de design auxiliar as comunidades no que se refere à valorização de seus produtos por meio da consolidação destes e utilizando-os como fator de diferenciação e competitividade. Para a consolidação desses produtos utilizam-se, sobretudo as funções do design como fatores de diferenciação e convencimento do público-alvo. $\mathrm{E}$ é a partir da aparência, juntamente com as imagens utilizadas para transmitir certas sensações, é que se deseja despertar nos usuários as noções de procedência e origem do produto, da identificação geográfica, bem como de elementos estéticos locais.

Isso permite a visualização dos benefícios dos conhecimentos em design e da aprendizagem, por parte dos atores sociais envolvidos, e sua atuação, para futura criação de produtos inovadores e serviços inexistentes, trazendo benefícios nos aspectos social, econômico e ambiental de acordo com a realidade da localidade.

Referente a este projeto envolvendo o município de Chapadão do Lageado, o NASDesign irá auxiliar na elaboração de artefatos de lembranças para comercialização, porém estes produtos devem priorizar a valorização da identidade local.

Como referência de projetos feitos com base em identidade local, temos o Programa Design Tropical da Amazônia (Figuras 14, 15 e 16), criado pelo Núcleo de Design Amazônico, o projeto visa a produção de artefatos com identidade regional que tem como objetivo tanto o resgate e valorização da arte e cultura indígena e cabocla, como o de técnicas e habilidades artesanais tradicionais. Além da criação de produtos de grande valor agregado, utiliza resíduos florestais como 
matéria prima.

Figura 14 - Design Tropical da Amazônia - Fruteira Girassol

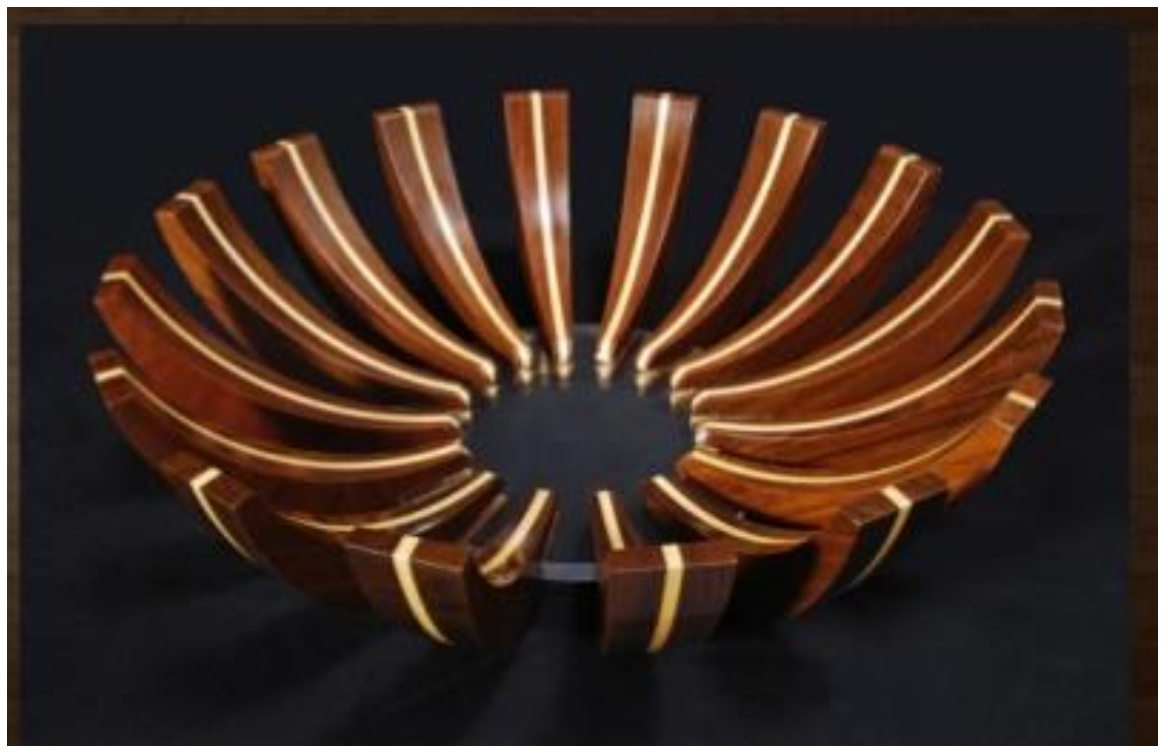

Fonte: GONÇALVES e MOUCO (2014)

Figura 15 - Design Tropical da Amazônia - Revisteiro cobra

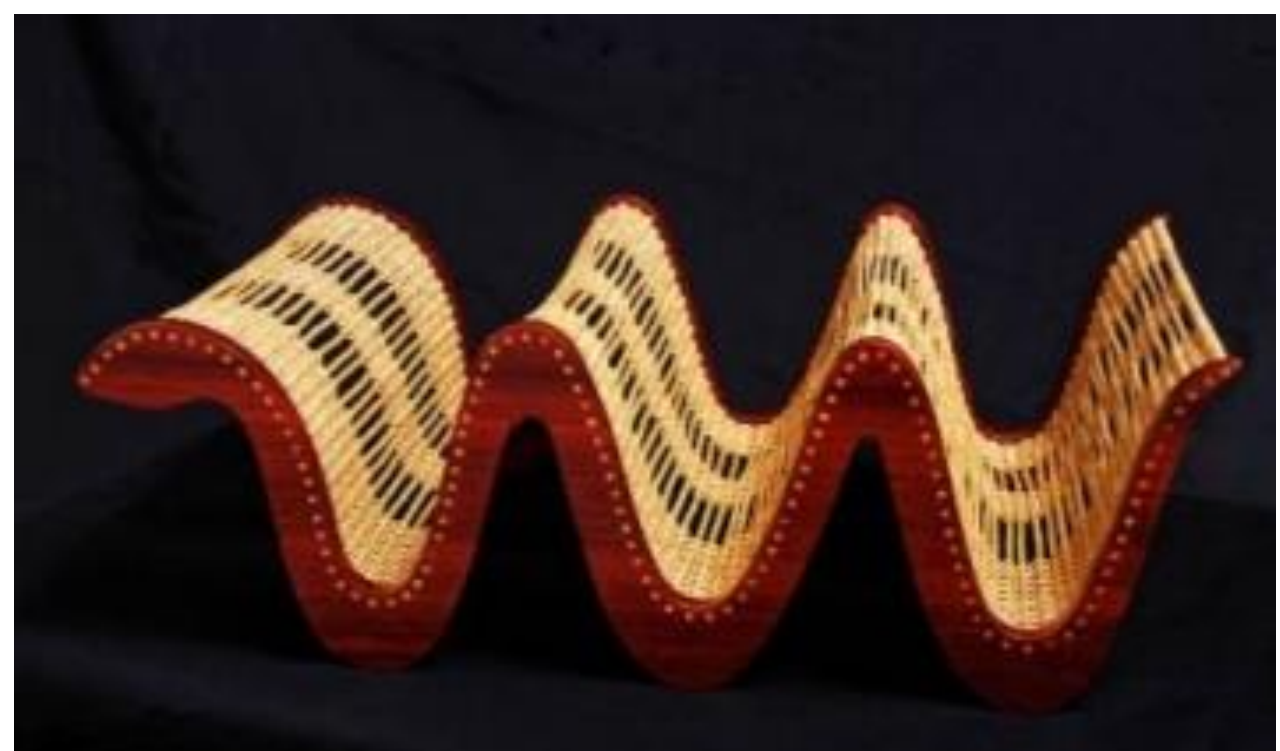

Fonte: GONÇALVES e MOUCO (2014) 
Figura 16 - Design Tropical da Amazônia -Apoio para livro onça

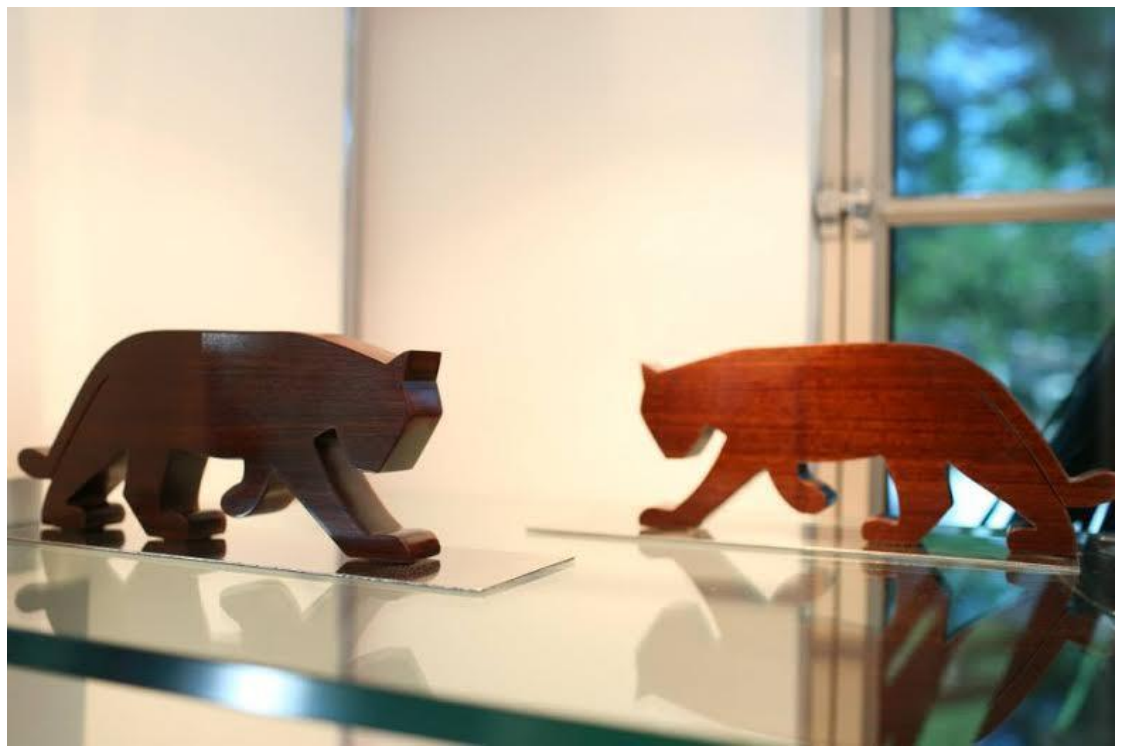

Fonte: GONÇALVES e MOUCO (2014)

No mesmo caminho de produtos inspirados em identidades locais, temos o Banco Lapa (Figura 17) e a Namoradeira Lapa (Figura 18). Criado pelos designers Alexandre Montenegro, Diogo Armond e Henrique Gomma, o produto foi, segundo eles "Inspirado nos famosos arcos do bairro boêmio do Rio de Janeiro, o Banco Lapa só falta ter sotaque carioca e ter samba no pé! "

Figura 17 - Banco Lapa

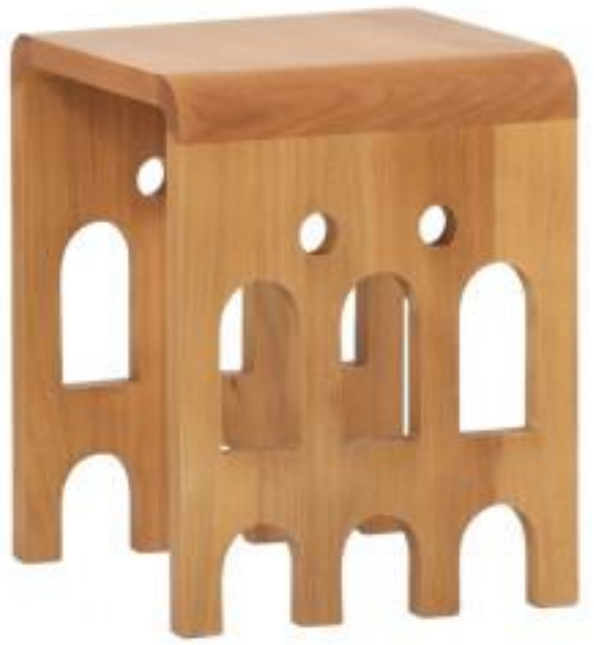

Fonte: https://www.fubba.com.br/banco-lapa (2012) 


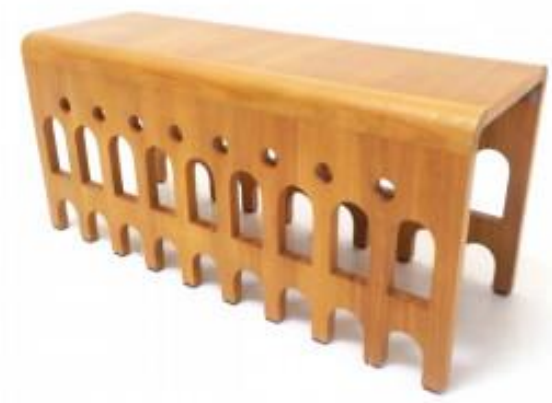

Fonte: https://www.fubba.com.br/namoradeira-lapa (2016)

Já o Banco Macaron (Figura 19), foi inspirado no típico doce francês de mesmo nome. Este produto é criação do estúdio Italiano Li Ving.

Figura 19 - Banco Macaron

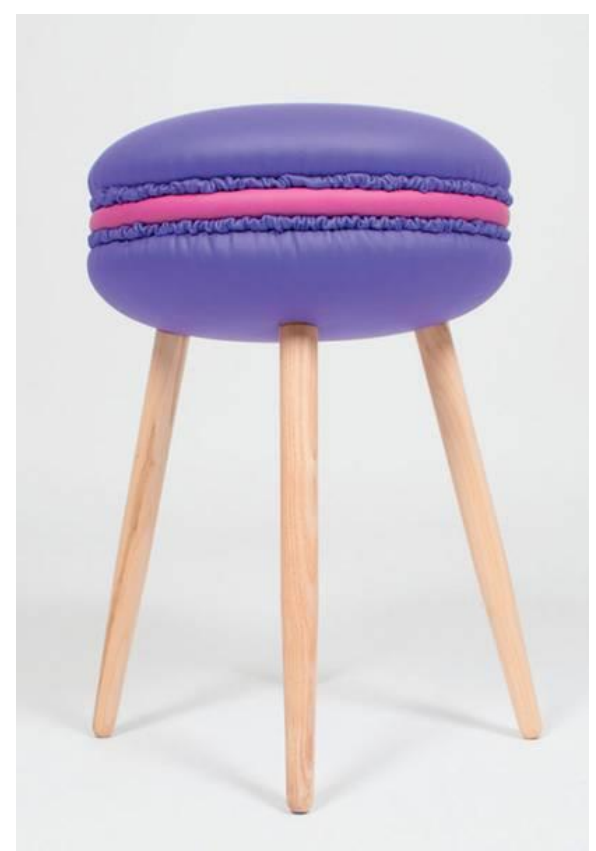

Fonte: http://blogs.diariodonordeste.com.br/design/moveis-compactos/banco-macaron (2015)

Como referência do Design gráfico, temos a identidade da cidade do Porto (Figuras 20 e 21), localizada em Portugal. Desenvolvida pelo White Studio, a nova identidade precisava facilitar a organização e simplificar a comunicação com os cidadãos. Com um estilo minimalista, o projeto foi inspirado nos famosos azulejos portugueses. 


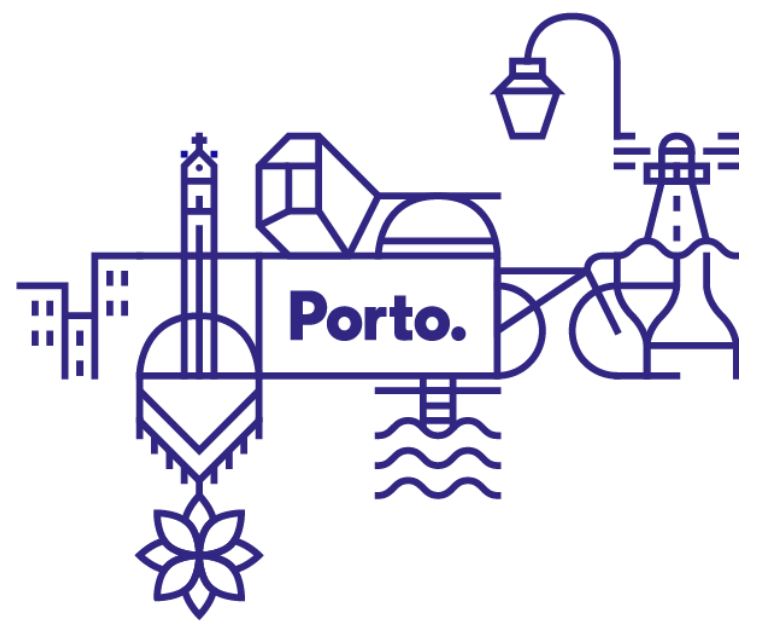

Fonte: http://designculture.com.br/portoeponto (2016)

Figura 21 - Identidade Cidade do Porto - Portugal

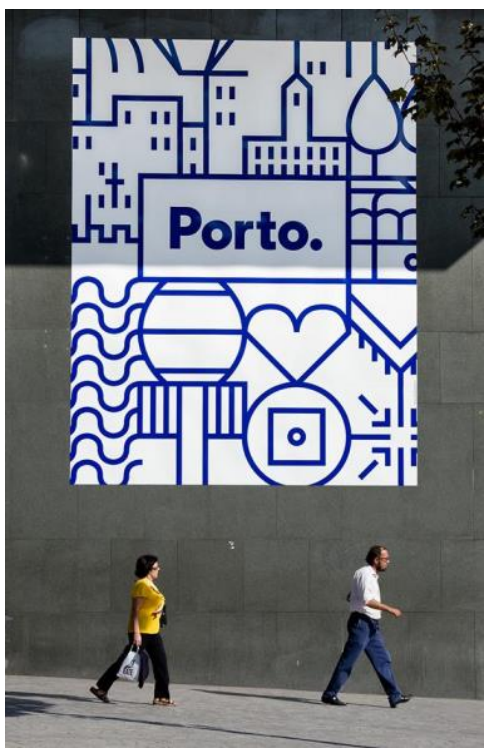

Fonte: http://designculture.com.br/portoeponto (2016)

\section{Considerações finais}

Este trabalho demonstra diversas possibilidades e aplicações a serem exploradas e desenvolvidas. Pois é um trabalho que irá continuar, seja pelo mesmo olhar, do próprio pesquisador, ou por outros olhares.

Em se tratando da pesquisa desenvolvida neste trabalho, vários fatores podem ser considerados relevantes pelo pesquisador, como, o estudo da história e da cultura do município de Chapadão do Lageado, localizado na região do alto vale do Itajaí, Santa Catarina, e a sua representação por meio de modelos iconográficos aplicados ao design, como fator estratégico de diferenciação e competitividade. 
Nesse sentido, a metodologia do design abordou três aspectos estratégicos de diferenciação, a pesquisa etnográfica a partir de levantamento de informações e imagens fotográficas com o objetivo da identificação cultural visual de raiz; o uso de mapas mentais e painéis semânticos para análise, organização e estruturação das informações a partir dos dados do mapa conceitual e painel semântico e o desenvolvimento de ícones determinado pela abstração e pela composição das formas baseadas no estilo Mono Crest.

Assim, este estudo, além de congregar aspectos culturais locais, processos, produtos e serviços, proporciona a estes, um diferencial que desperta o interesse da sociedade, pois agrega valor cultural que poderá ser materializado, no caso específico deste trabalho, por meio da aplicação de ícones e imagens em produtos de design.

Pretende-se futuramente realizar a produção de joias, eco joias, mobiliários, estampas e outros produtos identificados à comercialização e com isso, a valorização desses produtos e o fortalecimento da referência cultural de raiz do local. Essas imagens e formas iconográficas, serão o reconhecimento de elementos que caracterizavam esses povos além da representação simbólica dos povos mais antigos da região do Alto Vale, conferindo-Ihe identidade local e cultural de raiz.

O NASDesign utiliza conceitos e práticas de design que também são incorporados, constantemente, no desenvolvimento dos projetos com as comunidades, permitindo a visualização de benefícios e conhecimentos em design e da aprendizagem, por parte dos atores sociais envolvidos e sua atuação, para futura criação de produtos inovadores e serviços inexistentes, trazendo benefícios nos aspectos sociais, econômicos e ambientais, de acordo com a realidade da entidade.

\section{Referências}

BUZAN, T., 2005. Mapas mentais e sua elaboração: um sistema definitivo de pensamento que transformará a sua vida. São Paulo: Cultrix.

MANZINI, E; Vezzoli, C., 2008. O Desenvolvimento de Produtos Sustentáveis. 3rd ed. São Paulo: Editora da Universidade de São Paulo.

PANTONE, 2009. Pantone View Color Planner Summer 2010. Pantone Color System. INC PANTONE: pags, 92. United States.

GONÇALVES, Robervando; MOUCO, luçana. Projeto Design Tropical da Amazônia. 15 jul. 2014. 33 slides. Material apresentado no Debate Florestal sobre Ecossistemas de Negócios Florestais na Universidade do Estado do Amazonas.

OURIVES, Eliete Auxiliadora Assunção; KIST, Luisa; ROSA, Valéria Ilsa; FIGUEIREDO, Luiz Fernando Gonçalves de. Estudo iconográfico do Ribeirão da Ilha para aplicação no design de joias. In: II Conferência Internacional de Design, Engenharia e Gestão para inovação- IDEMi 2012. Florianópolis, 21-23 out. 2012.

AROS, Kammiri Corinaldesi; STRAIOTO, Ricardo Goulart Tredezini; FIGUEIREDO, Luiz Fernando Gonçalves de; SOUSA Richard Perassi Luiz de. Estilo gráfico monocrest em identidades visuais: uma análise da coerência entre a identidade visual e a imagem da marca. In: IV Conferência Internacional de Design, Engenharia e Gestão para inovação- IDEMi 2015. Florianópolis, 07-10 out. 2015. 